\title{
EXISTENCE OF SOLUTION FOR BIHARMONIC SYSTEMS WITH INDEFINITE WEIGHTS
}

\author{
GAURAV DWIVEDi
}

Abstract. In this article we deal with the existence questions to the nonlinear biharmonic systems. Using theory of monotone operators, we show the existence of a unique weak solution to the weighted biharmonic systems. We also show the existence of a positive solution to weighted biharmonic systems in the unit ball in $\mathbb{R}^{n}$, using Leray Schauder fixed point theorem. In this study we allow sign-changing weights.

Mathematics subject classification (2010): 35J08, 35J58, 35J60, 35J75, 35J91.

Keywords and phrases: biharmonic systems, Hardy-Rellich inequality, Green's function.

\section{REFERENCES}

[1] Adimurthi And S. Santra, Generalized Hardy-Rellich inequalities in critical dimension and its applications, Communications in Contemporary Mathematics 11, 3 (2009), 367-394.

[2] L.E. Andersson, T. ElfVing, AND G.H. Golub, Solution of biharmonic equations with application to radar imaging, J. Comp. and Appl. Math., 94, 2 (1998), 153-180.

[3] G.ARIoli, F. GAZZOLA AND H.C. GRUnAU, A semilinear fourth order elliptic problem with exponential nonlinearity, SIAM J. Math. Anal., 36, 4 (2005), 1226-1258.

[4] M.I.G. BLOOR AND M. J. WILson, Method for efficient shape parametrization of fluid membranes and vesicles, Physical Review E, 61, 4 (2000), 4218-4229.

[5] M.I.G. BLOOR AND M. J. WILSON, An approximate analytic solution method for the biharmonic problem, Proceedings of the Royal Society A: Mathematical, Physical and Engineering Science, 462, 2068 (2006), 1107-1121.

[6] T. Boggio, Sulle funzioni di Green d'ordinem, Rendiconti del Circolo Matematico di Palermo, 20, 1 (1905), 97-135.

[7] G. Bonanno, Some remarks on a three critical points theorem, Nonlinear Anal. T. M. A. 54, 4 (2003), 651-665.

[8] K.J. BROWN AND N. STAVRAKAKIS, Global bifurcation results for a semilinear elliptic equation on all of $\mathbb{R}^{n}$, Duke Math. J., 85, 1 (1996), 77-94.

[9] K.J.BROWN AND A. TERTIKAS, On the bifurcation of radially symmetric steady-state solutions arising in population genetics, SIAM J. Math. Anal., 22, 2 (1991), 400-413.

[10] N.P. CAC, A. M. Fink AND J. A. GatiCA, Nonnegative solutions of the radial Laplacian with nonlinearity that changes sign, Proceedings of the A. M. S. 123, 5 (1995), 1393-1398.

[11] R. CHEN, Existence of positive solutions for semilinear elliptic systems with indefinite weight, Electron. J. Differential Equations, 164 (2011), 1-8.

[12] N.T. ChUng, Multiple solutions for fourth order elliptic equation with Hardy type potential, Acta Universitatis Apulensis, 28 (2011), 115-124.

[13] P. Clément, B. De Pagter And G. Sweers, F. de Thélin, Existence of solutions to a semilinear elliptic system through Orlicz-Sobolev spaces, Mediterranean J. Math., 1, 1 (2004), 241-267.

[14] R. Dalmasso, Existence and uniqueness of positive solutions of semilinear elliptic systems, Nonlinear Anal. T. M. A., 39, 5 (2000), 559-568.

[15] D.G. De FIGUeIREDO AND B. RUF, Elliptic systems with nonlinearities of arbitrary growth, Mediterranean J. Math. 1, 4 (2004), 417-431. 
[16] P. Drabek And J. Milota, Methods of nonlinear analysis:applications to differential equations, Birkhäuser, 2nd edition, Basel, 2007.

[17] F. Gazzola, H.C. Grunau and G Sweers, Polyharmonic Boundary Value Problems: Positivity Preserving and Nonlinear Higher Order Elliptic Equations in Bounded Domains, Springer, Lecture notes in mathematics, 1991, Berlin, 2010.

[18] D.A. Gilberg And N.S. Trudinger, Elliptic partial differential equations of second order, Springer, 224, 2001.

[19] H.C. Granau, The Dirichlet problem for some semilinear elliptic differential equations of arbitrary order, Analysis, 11, 1 (1991), 83-90.

[20] H.C. GRUNAU AND G. SweERS, Classical solutions for some higher order semilinear elliptic equations under weak growth conditions, Nonlinear Anal. T. M. A., 28, 5 (1997), 799-807.

[21] D.D. HAI, Positive solutions to a class of elliptic boundary value problems, J. Math. Anal. Appl., 227, 1 (1998), 195-199.

[22] D.D. HAI AND R. ShIVAJI, An existence result on positive solutions for a class of semilinear elliptic systems, Proceedings of the Royal Society of Edinburgh: Section A Mathematics, 134, 01 (2004), 137-141.

[23] D.D. HAi AND R. ShivaJi, Uniqueness of positive solutions for a class of semipositone elliptic systems, Nonlinear Anal. T. M. A., 66, 2 (2007), 396-402.

[24] N. LAM AND G. LU, Existence of nontrivial solution to polyharmonic equations with subcritical and critical exponential growth, Discrete and Continuous Dynamical Systems, 32, 6 (2012), 2187-2205.

[25] A.C. LAZER AND P. J. MCKenNa, Large-amplitude periodic oscillations in suspension bridges: some new connections with nonlinear analysis, Siam Review, 32, 4 (1990), 537-578.

[26] P.L. LIONS, On the existence of positive solutions of semilinear elliptic equations, SIAM review, 24, 4 (1982), 441-467.

[27] Y. LIU AND Z. WANG, Biharmonic equations with asymptotically linear nonlinearities, Acta Mathematica Scientia, 27, 3 (2007), 549-560.

[28] E. Mitidieri, A simple approach to Hardy inequalities, Springer, Mathematical Notes, 67, 4 (2000), 479-486.

[29] J.A. Peles Ko And D. H. Bernstein, Modeling Mems and Nems, CRC press, 2002.

[30] F. RELliCh, Halbbeschränkte Differentialoperatoren höherer Ordnung, Proceedings of the International Congress of Mathematicians, (3), (1954), 243-250.

[31] N.E. Sevant, M.I.G. Bloor And M. J. Wilson, Aerodynamic design of a flying wing using response surface methodology, Journal of Aircraft, 37, 4 (2000), 562-569.

[32] Y.T. SHEN AND Y.X. YAO, Nonlinear elliptic equations with critical potential and critical parameter, Proceedings of the Royal Society of Edinburgh: Section A Mathematics, 136, 5 2006, 1041-1051.

[33] S. Timoshenko And W.K. Sergius, Theory of plates and shells, McGraw-hill, $2^{\text {nd }}$ Edition, New York, 1959.

[34] F. Tомі, Über elliptische Differentialgleichungen 4. Ordnung mit einer starken Nichtlinearität, Nachr. Akad. Wiss. G ottingen II. Math-Phys. Klasse, (1976), 33-42.

[35] J. TYAGI, Existence of nonnegative solutions for a class of semilinear elliptic systems with indefinite weight, Nonlinear Anal. T. M. Appl., 73, 9 (2010), 2882-2889.

[36] Y. WANG AND Y. SHEN, Nonlinear biharmonic equations with Hardy potential and critical parameter, J. Math. Anal. Appl., 355, 2 (2009), 649-660.

[37] R. WolfGAng AND T. WeTh, Existence of solutions to nonlinear, subcritical higher order elliptic Dirichlet problems, J. Differential Equations, 248, 7 2010, 1866-1878.

[38] H. XIE AND J. WANG, Infinitely many solutions for p-harmonic equation with singular term, Journal of Inequalities and Applications, 2013, 1 (2013), 9.

[39] H.Xiong AND Y.T. SHEN, Nonlinear biharmonic equations with critical potential, Acta Mathematica Sinica 21, 6 (2005), 1285-1294.

[40] Y. YAO, R. WANG AND Y. SHEN, Nontrivial solution for a class of semilinear biharmonic equation involving critical exponents, Acta Mathematica Scientia, 27, 3 (2007), 509-514. 